\title{
Valve Location Method for Evaluating Drain Efficiency in Water Transmission Pipelines
}

\author{
Byoung-Ho Shin ${ }^{1}$, Doo Yong Choi ${ }^{1}$, Kwansue Jung ${ }^{2}$ and Zong Woo Geem ${ }^{3, *(\mathbb{D})}$ \\ 1 Korea Water Resources Corporation (K-Water), Daejeon 34045, Korea; sbh@kwater.or.kr (B.-H.S.); \\ dooyong@kwater.or.kr (D.Y.C.) \\ 2 Department of Civil Engineering, Chungnam National University, Daejeon 34134, Korea; ksjung@cnu.ac.kr \\ 3 Department of Energy IT, Gachon University, Seongnam 13120, Korea \\ * Correspondence: geem@gachon.ac.kr
}

Received: 23 August 2020; Accepted: 30 September 2020; Published: 3 October 2020

\begin{abstract}
Water transmission pipelines, which transport bulk water into storage facilities, usually have a tree-type configuration with large dimensions; thus, the breakage of a pipeline may cause a catastrophic service interruption to customers. Although drain efficiency is closely related to the number of washout and control valves and their locations, there is no useful guideline. This paper proposes a valve locating method by introducing numerical analyses to enumerate drainage time and zone. A time integration method, combined with the Newton-Raphson algorithm, is suggested to resolve drainage time, while considering the friction loss in gravitational flow. A drain direction matrix, which shows drain direction and coverage, is derived using a network searching algorithm. Furthermore, a feasible practical approach is presented by introducing a critical horizontal slope, a major washout valve, drainage indices, and control valve embedment. The developed method is first applied to simple pipes to validate the drainage time module. Subsequently, the model is expanded to the CY transmission line, which is one of the BR water supply systems in South Korea currently in operation. The results reveal that three drain valve locations have been neglected, and the addition of control valves guarantees consistent drain time below the operational criteria.
\end{abstract}

Keywords: water transmission; drain efficiency; valve location; drainage time; pipe breakage

\section{Introduction}

A water transmission pipeline conveys bulk water into service areas or storage facilities and is characterized by a tree system configuration, which then branches off into distribution mains. Despite the simplicity of the water transmission layout, pipeline breakage causes severe service interruption that affects a wide service area due to its supply coverage. Furthermore, repairs take a long time, owing to the dimensions of the large-scale pipelines. However, the innate properties of a large-scale transmission line makes it difficult for water utility companies to design an arterial loop or grid system to transport water from an alternate route. Therefore, strategic valve location is critical to reduce unplanned interruption time from the start of failure to the restoration of water supply.

Almost $80 \%$ of water utility investment is committed to water transmission and distribution systems, but little attention has been paid to measuring the performance of the system until Deb et al. [1] first published their manual in the American Water Works Association (AWWA) Research Foundation. Recent advances in information and communications technology (ICT) have led to the development of relevant technologies in detecting anomalies such as leaks, water main breakages, pipe blockages in water distribution systems. Many approaches have been proposed to locate and size anomalies by using real-time monitoring data, and to evaluate system reliability. These studies include transient test-based techniques [2,3], artificial intelligence models [4-6], and other hybrid approaches [7-9]. 
In particular, the recent developed models showed the possibility as powerful tools for localizing anomalies enabled in real pipe system $[3,6,9]$. In the meantime, Bouchart and Goulter [10] addressed the role of a valve, which minimizes the failure impact in a water distribution system. Walski [11] also recognized the importance of valves in improving the reliability of distribution systems and developed a segment method to identify valves and isolate pipe systems. Later, Hoff [12] focused on practical considerations related to valve maintenance, selection, and installation. Ysusi [13] provided a comprehensive review of pipeline and valve design in a water distribution system. He also discussed the positioning of control valves and the selected valve interval for large-diameter transmission pipelines. For a water distribution system with a grid or looped layout, the publication of the AWWA Research Foundation and subsequent research [14-18] provided the valve location criteria and their effect on system reliability. Furthermore, optimization methods for locating valves and calibrating valve settings have been continually proposed for providing better solutions [19-21]. To date, however, there has been no research on efficiently managing the duration of service interruption by strategically placing valves in water transmission lines.

In many countries with limited water sources that are far away from urban areas, long and large-scale transmission lines are common for drinking water systems. Although storage reservoirs and/or tanks can be placed to securely provide water in emergencies, water utilities need to control the duration of service interruptions regardless of planned and pre-notified maintenance. Unplanned accidents involving transmission lines in Korea over a 10 year period, from 2007 to 2016, were investigated by Shin [22], and it was reported that $12 \%$ of 153 accidents resulted in service interruptions to end users, which implies that long-lasting interruptions can exceed the capacity of storage. From the survey conducted by Shin, it was reported that the total duration of repair work consists of draining water, repairing damages, and refilling water; draining and refilling the water accounts for half of the repair time. In other words, optimally controlling the drainage time by restricting the drainage zone and time is indispensable for efficiently managing the durations of repair and service interruption. Usually, the drainage zone and time can be controlled by installing a washout valve (or drain valve) and control valve (or shut-off or isolation valve) at regular distances in the water transmission system.

In this study, a valve location method is proposed by introducing a network searching algorithm for the purpose of enumerating the drainage zone, and a numerical time integration method is employed to calculate drainage time, while incorporating the friction effect for gravitational flow. A conventional orifice equation is reconstructed for calculating the drainage time considering the energy loss induced by internal pipe friction. The resulting nonlinear equation is numerically resolved with the Newton-Raphson iteration. The valve location method pursues a more systematic approach compared to conventional rule of thumb, in which a washout valve is installed at the low point to drain sediment or excess water from the transmission main, and the control valve is positioned at a regular interval (e.g., 1-3 km in Korean and Japanese standards). To quantify the drainage properties of the transmission line, a drain direction matrix, drainage coverage index, and drainage time index are proposed. Special attention is given to the treatment of a horizontally sloped pipe that can be drained with bidirectional flow. Then, the time integration method is validated with examples, which focus on the incorporation of friction effects. The developed method is implemented on one of the BR multi-regional water transmission lines to examine its applicability to real water systems.

\section{Time Integration Method for Calculating Drainage Time}

The most important factor in locating washout and control valves is drainage time because reduction and consistency in drainage time can eventually guarantee a reduction in the duration of service interruption. A precise estimation of the drainage time can be significant because pipes in the transmission line have a large diameter and are long. There is typically a great distance between the water source and storage tanks in a water transmission line; therefore, frictional head loss in the pipeline will affect the delay of gravitational flow while draining the water in the pipe. In other words, 
a conventional drainage time calculation, originating from the orifice equation, needs to be revised with consideration to the energy loss induced by internal friction. In this section, a theoretical governing equation is derived by incorporating the friction effect, and a numerical model to estimate drainage time is presented.

\subsection{Governing Equation of Pipe Drainage Considering Friction Loss}

In Figure 1a, the draining time at the water level of $h$ (shown as $h_{n}^{t}$ in the figure) is calculated using the orifice equation derived from Bernoulli's theorem as follows:

$$
Q=a c \sqrt{2 g h}
$$

where $a$ is the cross-sectional area of the orifice $\left(=\frac{\pi d^{2}}{4}\right), \mathrm{c}$ is the flow coefficient of the orifice, and $g$ is the gravitational acceleration. Considering the friction head loss of $h_{L}$, the orifice equation can be revised as follows:

$$
Q=a c \sqrt{2 g\left(h-h_{L}\right)}
$$

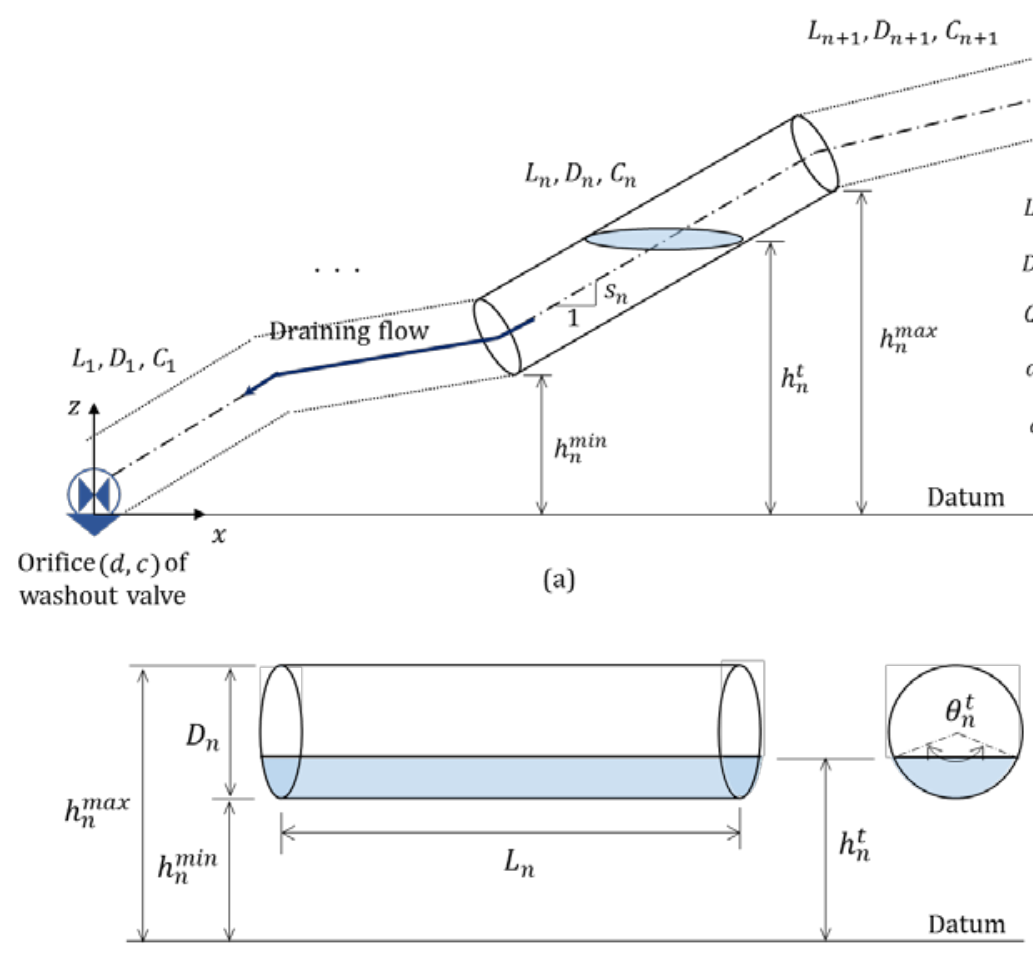

(b)

Figure 1. Schematic diagram of pipe drainage: (a) a sloped pipe with neighboring ones; (b) a horizontal pipe and cross-section.

In the equation above, the friction head loss can be expressed in terms of volume flowrate as follows:

$$
h_{L}=K Q^{m}
$$

where $K$ is the pipe coefficient, which is a function of the pipe length $(L)$, diameter $(D)$, and roughness coefficient $(C)$, and $m$ is the exponent depending on the friction formula, which is 1.852 for the Hazen-Williams equation and 2.0 for the Manning equation. By inserting Equation (3) into Equation (2), the following nonlinear equation can be derived:

$$
f(Q)=Q^{2}+2 g a^{2} c^{2} K Q^{m}-2 g a^{2} c^{2} h=0
$$


From the conservation of mass, as shown in Figure 1a, the volume flowrate from the pipe perpendicular to the horizon can also be expressed as follows:

$$
Q=-A \frac{d h}{d t}
$$

where $A$ is the cross-sectional area, denoted as $A=\frac{\pi D^{2}}{4} \frac{\sqrt{1+s^{2}}}{s}$ when a pipe has a slope of $s$ and a diameter of $D$. As shown in Figure 1b, the cross-sectional area can be denoted as $A=\frac{D^{2}}{8}(\theta-\sin \theta)$ when a pipe has a horizontal slope and an angle of $\theta$ (shown as $\theta_{n}^{t}$ in the figure). Combining Equations (4) and (5) provides the solution of drainage time in consideration of friction loss, but the nonlinearity in terms of flowrate in Equation (4) needs to be induced with numerical approximation.

\subsection{Time Integration with Numerical Iteration}

In order to resolve the nonlinear solution in Equation (4), the Newton-Raphson method is implemented to find the root using derivatives as follows.

$$
Q_{j+1}=Q_{j}-\frac{f\left(Q_{j}\right)}{f^{\prime}\left(Q_{j}\right)}
$$

The Newton-Raphson formula consists of extending the tangent line at a current point $Q_{j}$ until it crosses zero; then, the next guess is $Q_{j+1}$. In Equation (6), the derivative can be found from Equation (4) as follows:

$$
f^{\prime}(Q)=2 Q+2 g m a^{2} c^{2} K Q^{m-1}
$$

Once the root-finding is completed with the Newton-Raphson iteration at a specific time $t$, the time integration method should be embedded to calculate the drainage volume of $Q d t$ (or $-A d h$ ) in Equation (5). This is because the water level decreases over time, and the decrease in volume flowrate should be reflected to accurately calculate the drainage time. Therefore, it is necessary to discretize a small amount of the finite time step and subsequently add the time step until the water level reaches a minimum. In this study, an explicit time integration method is employed with a finite time step, $\Delta t$, of $1 \mathrm{~min}$.

The numerical procedure of the time integration method incorporated with the Newton-Raphson iteration is presented in Figure 2. For the first of the numerical steps, the time step was set and a pipe was selected for the calculation. While draining the excess water in a pipe, the drained water passes through downstream pipes with different pipe properties. When calculating the drainage time of the $n$-th pipe from the washout valve in Figure 1a, a group of pipe data $i=1,2, \cdots, n$ is required because they are on the drainage route. On the other hand, pipe data for $i=n+1$ is not needed because the $(n+1)$-th pipe is positioned at a higher elevation than the $n$-th pipe. In addition to pipe data, node elevation and washout valve data linked by pipe $i=1,2, \cdots, n$ are loaded as input data. Once all the data are uploaded, a higher elevation node between the two nodes connected to the $n$-th pipe is chosen to calculate the initial water level, $h_{n}^{\max }$, by taking the difference between the elevations of the washout valve and selected node. Using the Newton-Raphson iteration, the initial flowrate, $Q_{n}^{t=0}$, is determined, thus resulting in drainage volume, $\Delta V_{n}^{t}$, by multiplying time step, $\Delta t$. From the volume calculated, water level, $h_{n}^{t}$, can be updated, and the pipe coefficient, $K_{n}^{t}$, can also be recalculated using the updated pipe length, $L_{n}^{t}$, for a sloped pipe, or the updated pipe diameter (more specifically hydraulic radius), $D_{n}^{t}$, for a horizontal pipe. Note that only the properties of the $n$-th pipe vary over time in serially connected pipes. In other words, the properties of the other pipes, $i=1,2, \cdots, n-1$, are constant over the simulation because the numerical procedure is stopped when the water level, $h_{n}^{t}$, is less than the minimum water elevation, $h_{n}^{\min }$, which is calculated from a lower elevation node of 
the $n$-th pipe. Reflecting the time integration procedure, Equations (3), (4), and (7) can be revised in a serially connected pipeline, $i=1,2, \cdots, n$ at a specific time, $t$, as follows:

$$
\begin{gathered}
h_{L}^{t}=\left(\sum_{i=1}^{n-1} K_{i}+K_{n}^{t}\right)\left(Q_{n}^{t}\right)^{m} \\
f\left(Q_{n}^{t}\right)=\left(Q_{n}^{t}\right)^{2}+2 g a^{2} c^{2}\left(\sum_{i=1}^{n-1} K_{i}+K_{n}^{t}\right)\left(Q_{n}^{t}\right)^{m}-2 g a^{2} c^{2} h_{n}^{t}=0 \\
f^{\prime}\left(Q_{n}^{t}\right)=2 Q_{n}^{t}+2 g m a^{2} c^{2}\left(\sum_{i=1}^{n-1} K_{i}+K_{n}^{t}\right)\left(Q_{n}^{t}\right)^{m-1}
\end{gathered}
$$

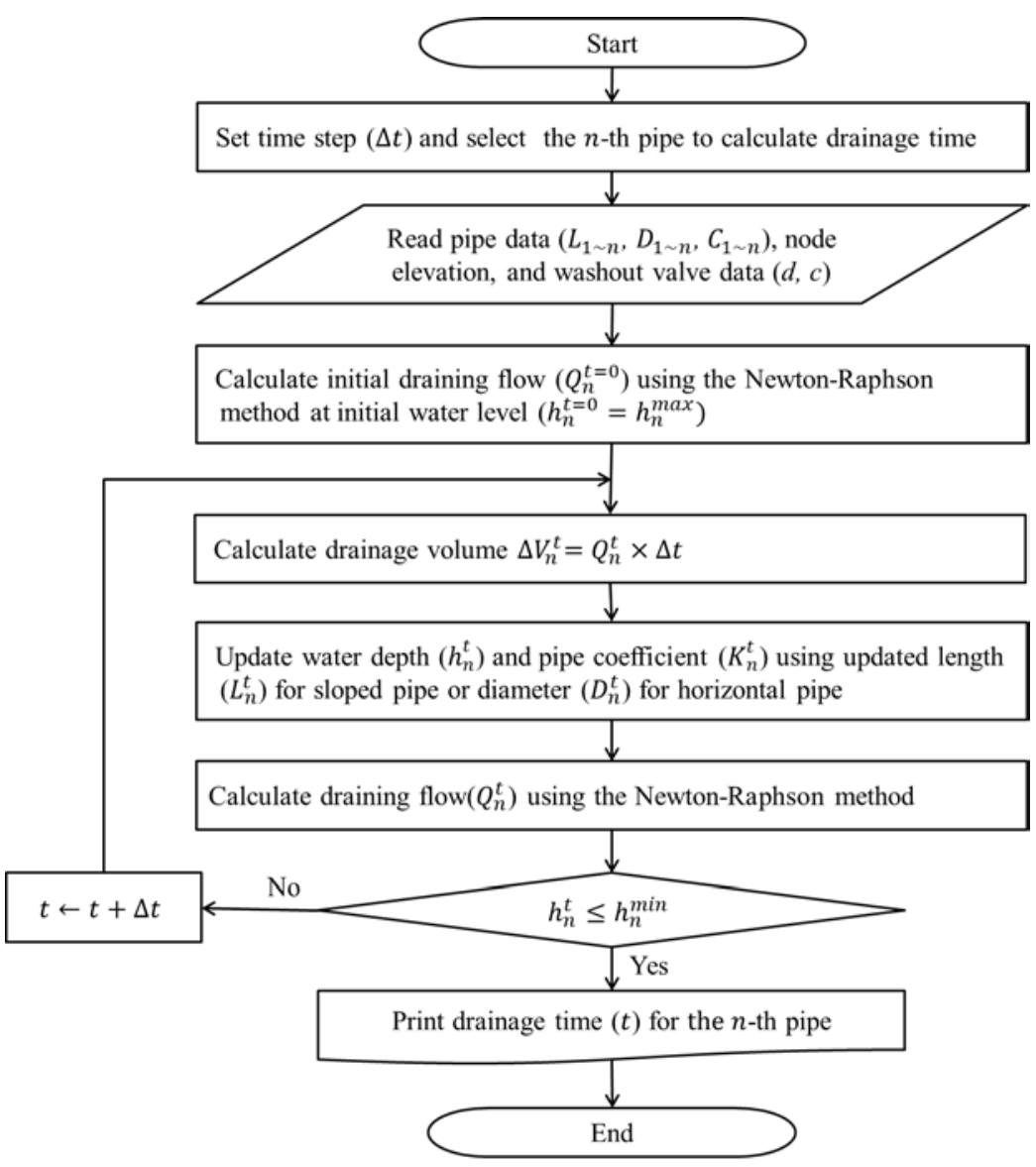

Figure 2. Numerical procedure of time integration in calculating drainage time.

\section{Valve Location Method for Improving Drain Efficiency}

In the hydraulic modeling of water transmission or water distribution systems, network data should be prepared to represent the characteristics of a pipeline including dimensions, roughness, and elevation. Similar to hydraulic modeling, the network for the proposed valve location is composed of two primary types: pipe and node data. The only difference is that nodes in this network are classified into junctions, drain valves, and control valves, as shown in Figure 3. In this section, we explain how drainage indices are defined to evaluate drain efficiency in the network, and how the proposed method is implemented. 


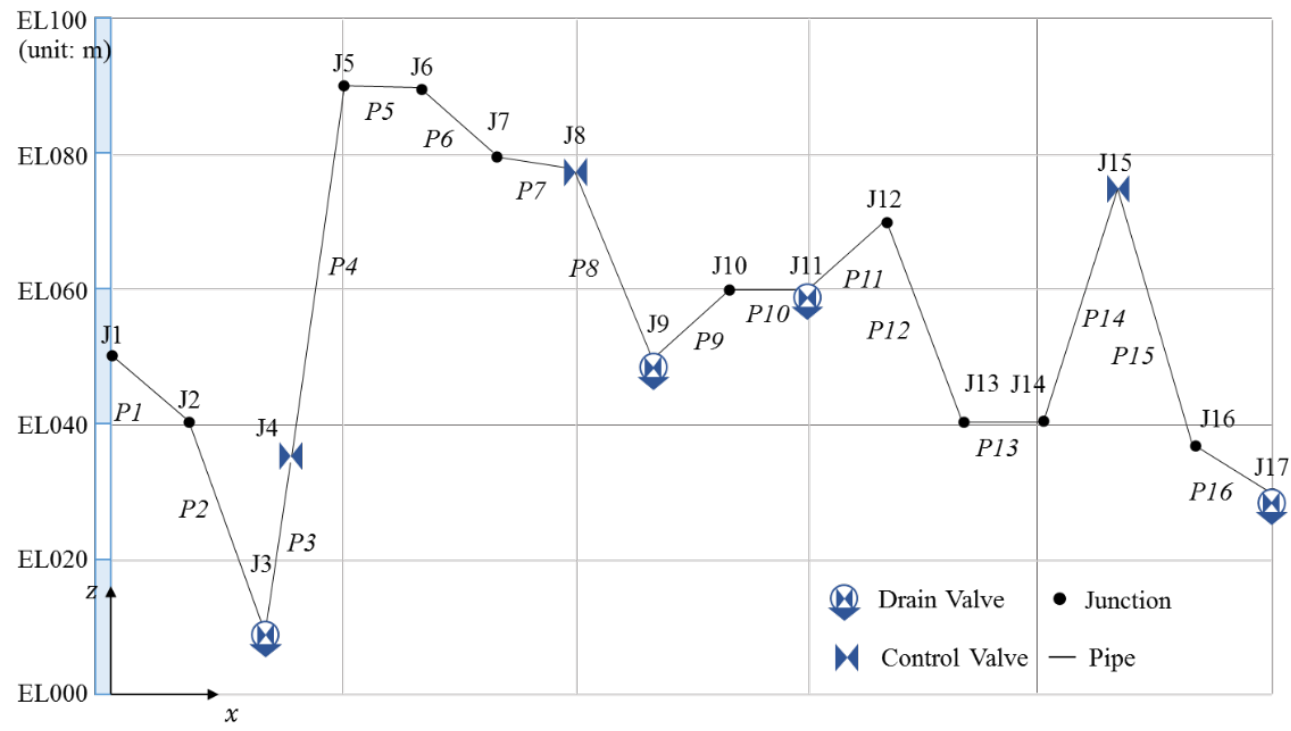

Figure 3. Network representation of a sample water transmission line.

\subsection{Defining Drainage Indices}

In order to effectively evaluate drain efficiency in the transmission line, two indices are suggested in terms of drainage coverage and time. In Figure 3, excess water in the network should be drained within an allowable time no matter where pipe breakage occurs. Therefore, the following indices are suggested: a drain coverage index, representing spatial efficiency, and a drainage time index, representing temporal efficiency.

\subsubsection{Drainage Coverage Index (DCI)}

The drainage zone, which is capable of being drained from the total pipeline length through washout valves during pipe breakage, is defined as follows:

$$
I_{C}=\frac{\sum_{j=1}^{N D} L_{j}}{L_{\text {total }}}
$$

where $L_{j}$ is the pipe length to be drained through the washout valve $j, N D$ denotes the number of washout valves installed, and $L_{\text {total }}$ is the total pipe length to be analyzed in the network. In practice, DCI $\left(I_{C}\right)$ should be " 1 "; otherwise, a value of less than " 1 " indicates a fault in the planning of the water transmission line. Therefore, DCI can be effectively utilized to find a planning error and revise it. When a pipe segment can be drained through water storage facilities such as a storage tank or service reservoir, it can be included in the pipe length of $L_{j}$. This is because the facilities can be regarded as a virtual washout valve.

\subsubsection{Drainage Time Index (DTI)}

The maximum allowable drainage time $\left(T_{\max }\right)$ is related to the time of service interruption and service quality provided by water utilities. Every water utility should maintain less than the maximum time to avoid extended service interruption. Therefore, every drainage zone should be evaluated to determine whether the estimated drainage time is within the maximum time. Furthermore, it is necessary for water utility companies to evaluate the entire water transmission line. In this study, DTI $\left(I_{T}\right)$ is defined as follows.

$$
I_{T}=\frac{\sum_{j=1}^{N D}\left[2-M A X\left(1, \frac{T_{j}}{T_{\max }}\right)\right]}{N D}
$$


where $M A X()$ denotes the larger value out of 1 and $T_{j} / T_{\max }$, in which $T_{j}$ is drainage time at the washout valve $j$. DTI also expresses the uniformity of drainage time for the whole water transmission line. If $T_{j}$ is larger than $T_{\max }$, then $\operatorname{MAX}\left(1, T_{j} / T_{\max }\right)$ and the inside value of the square brackets will have more than " 1 " and less than " 1 ", respectively. A value of less than " 1 " indicates the existence of problematic zones in terms of drain time. In other words, DTI becomes " 1 " if drainage time $\left(T_{j}\right)$ is less than or equal to $T_{\max }$ at all the washout valves installed.

\subsection{Procedure for the Valve Location Method}

The proposed method for locating washout and control valves can be applied to the operation stage as well as the design stage, because the method suggests an additional valve location for existing water transmission lines. The procedure for the valve location method is presented in Figure 4. A detailed description of each process is explained using the sample transmission line in Figure 3 as follows.

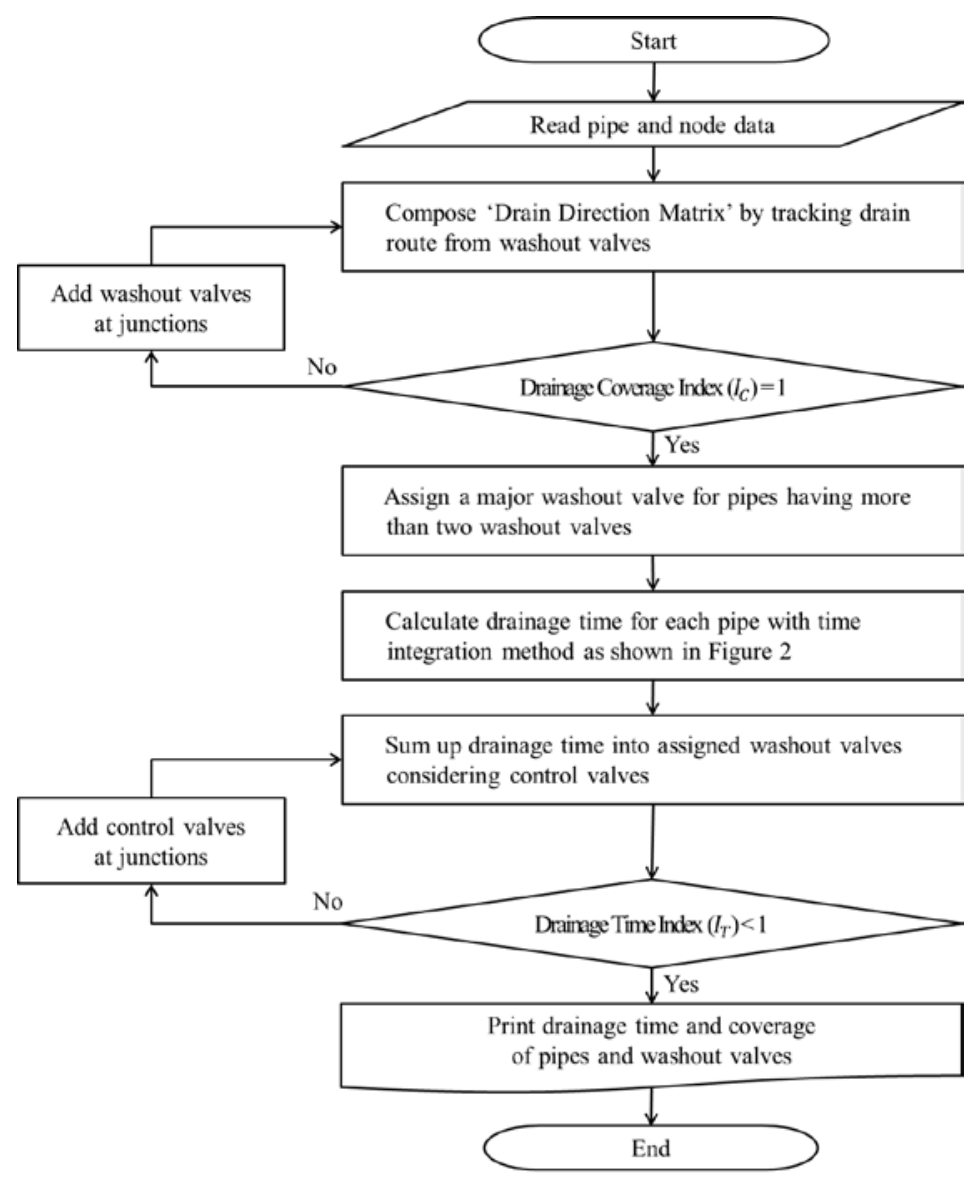

Figure 4. Proposed procedure for the valve location method.

\subsubsection{Input Data}

Input data from hydraulic modeling can also be utilized, as listed in Table 1. In this method, the following pipe data are required: pipe number (ID); start and end nodes (node 1 and node 2); length representing the length of the segment between the nodes (Length in $\mathrm{m}$ ); diameter representing the pipe size (diameter in $\mathrm{mm}$ ); and roughness coefficient referring to the degree of roughness of the interior surface of the pipe (roughness). In addition, the following node data are required: node number (ID); elevation above sea level or the standard reference (Elev in $\mathrm{m}$ ); type of nodes out of junction (Type); washout valve (DV); control valve (CV); diameter of the washout valve (orifice diameter in $\mathrm{mm}$ ); 
and flow coefficient of the washout valve (orifice coefficient). Comparing hydraulic modeling data, only type, orifice diameter, and orifice coefficient are expected to be added for the simulation.

Table 1. Input file for the valve location method.

\begin{tabular}{ccccccccccc}
\hline \multicolumn{2}{c}{ (NODES) } & \multicolumn{7}{c}{ (PIPES) } \\
\hline ID & Elev & Type & $\begin{array}{c}\text { Orifice } \\
\text { Diameter }\end{array}$ & $\begin{array}{c}\text { Orifice } \\
\text { Coefficient }\end{array}$ & ID & Node1 & Node2 & Length & Diameter & Roughness \\
\hline J1 & 50.0 & & & & P1 & J1 & J2 & 800 & 1200 & 120 \\
J2 & 40.0 & & & & P2 & J2 & J3 & 1200 & 1200 & 120 \\
J3 & 10.0 & DV & \multirow{2}{*}{300} & 0.8 & P3 & J3 & J4 & 500 & 1200 & 120 \\
J4 & 35.0 & CV & & & P4 & J4 & J5 & 1000 & 1200 & 120 \\
J5 & 90.0 & & & & P5 & J5 & J6 & 300 & 1500 & 130 \\
J6 & 89.7 & & & & P6 & J6 & J7 & 800 & 1000 & 100 \\
J7 & 80.0 & & & & P7 & J7 & J8 & 1000 & 1000 & 100 \\
J8 & 78.0 & CV & & & P8 & J8 & J9 & 1000 & 1000 & 100 \\
J9 & 50.0 & DV & 250 & 0.8 & P9 & J9 & J10 & 700 & 1000 & 100 \\
J10 & 60.0 & & & & P10 & J10 & J11 & 1300 & 1000 & 100 \\
J11 & 59.8 & DV & 250 & 0.8 & P11 & J11 & J12 & 1000 & 1000 & 100 \\
J12 & 70.0 & & & & P12 & J12 & J13 & 500 & 1000 & 100 \\
J13 & 40.0 & DV & \multirow{2}{*}{300} & 0.9 & P13 & J13 & J14 & 500 & 1000 & 100 \\
J14 & 40.1 & & & & P14 & J14 & J15 & 1000 & 1000 & 100 \\
J15 & 75.0 & CV & & & P15 & J15 & J16 & 1000 & 1000 & 100 \\
J16 & 37.0 & & & & P16 & J16 & J17 & 800 & 1000 & 100 \\
J17 & 30.0 & DV & 250 & 0.8 & & & & & & \\
\hline
\end{tabular}

\subsubsection{Identification of Drainage Coverage Using the Drain Direction Matrix}

In this study, the so-called drain direction matrix is introduced to trace the drainage zone of pipes from a washout valve. The direction matrix represents the set of pipes draining into a washout valve by comparing the elevations of the start and end nodes. The following stepwise procedure explains the algorithm used to compose the matrix:

Step 1: Select a washout valve from the node data.

Step 2: Select pipes linked to the selected node.

Step 3: Select another node that is not the washout valve node, and compare the elevation of two nodes at the pipe.

Step 4: If the other node has a higher elevation than the drain node (washout valve node), then repeat the search with the same procedure as Steps 1 to 3 by adopting the other node as a new drain node.

Otherwise, the searching process is stopped because drainage is not possible in an adverse slope. Step 5: Repeat Steps 1 to 4 for all washout valves.

The resulting drain direction matrix from the input data listed in Table 1 is shown in Table 2a. In the matrix, the draining direction can be identified with a value of " 1 " for the normal flow direction and " -1 " for the reverse flow direction, for which node 1 should be upstream of node 2 in the pipe data.

The above procedure is the reason for the sloped pipe. In an extremely mild slope, however, it is meaningless to discern between two neighboring nodes, and can be regarded as a horizontally sloped pipe. Therefore, the concept of the critical horizontal slope $\left({ }^{C}{ }^{C R}\right)$ is introduced by defining the elevation difference of two nodes to be equivalent to a quarter of the diameter in a pipe $i$ as follows:

$$
s_{i}^{C R}=\frac{D_{i}}{4 \times \sqrt{L_{i}^{2}-\left(h_{i}^{\text {max }}-h_{i}^{\text {min }}\right)^{2}}}
$$

If the absolute value of slope in a pipe is smaller than the critical horizontal slope, it can be regarded as a horizontally sloped pipe with a slope of " 0 ". It should be noted that bidirectional searching can be possible if a pipe has a horizontal slope, regardless of a slight difference in node 
elevations. For example, the P5 and P10 pipes in Table 2a are regarded as horizontally sloped pipes; thus, they have two drain nodes with different signs $(+1,-1)$ at J3 and J9, J9 and J11, followed by bidirectional searching, respectively. Once the drain direction matrix is composed, as shown in Table 2a, the drain coverage index can be found easily by counting the number of pipes that are not filled with " -1 " or " 1 ". In the sample case, $I_{C}=11,400 \mathrm{~m} / 13,400 \mathrm{~m}=0.851$ from Equation (11), and more drain valves are needed to drain excess water from pipes P12, P13, and P14. After adding the washout valve at junction J14, an updated drain direction matrix can be composed, as shown in Table $2 \mathrm{~b}$.

Table 2. Drain direction matrix of a sample pipeline.

\begin{tabular}{|c|c|c|c|c|c|c|c|c|c|c|c|c|c|c|c|c|}
\hline \multicolumn{17}{|c|}{ (a) Original input data } \\
\hline & P1 & P2 & P3 & P4 & P5 & P6 & P7 & P8 & P9 & P10 & P11 & $\mathrm{P} 12$ & P13 & P14 & P15 & P16 \\
\hline $\mathrm{J} 3$ & -1 & -1 & 1 & 1 & 1 & & & & & & & & & & & \\
\hline J9 & & & & & -1 & -1 & -1 & -1 & 1 & 1 & 1 & & & & & \\
\hline $\mathrm{J} 11$ & & & & & & & & & & -1 & 1 & & & & & \\
\hline $\mathrm{J} 17$ & & & & & & & & & & & & & & & -1 & -1 \\
\hline \multicolumn{17}{|c|}{ (b) After adding one more washout valve at node J13 } \\
\hline & P1 & P2 & P3 & P4 & P5 & P6 & P7 & P8 & P9 & P10 & P11 & P12 & P13 & P14 & P15 & P16 \\
\hline $\mathrm{J} 3$ & -1 & -1 & 1 & 1 & 1 & & & & & & & & & & & \\
\hline J9 & & & & & -1 & -1 & -1 & -1 & 1 & 1 & 1 & & & & & \\
\hline $\mathrm{J} 11$ & & & & & & & & & & -1 & 1 & & & & & \\
\hline $\mathrm{J} 14$ & & & & & & & & & & & & -1 & -1 & 1 & & \\
\hline $\mathrm{J} 17$ & & & & & & & & & & & & & & & -1 & -1 \\
\hline \multicolumn{17}{|c|}{ (c) After assigning a major washout valve for pipes with multiple valves } \\
\hline & P1 & P2 & P3 & P4 & P5 & P6 & P7 & P8 & P9 & P10 & P11 & P12 & P13 & P14 & P15 & P16 \\
\hline $\mathrm{J} 3$ & -1 & -1 & 1 & 1 & 1 & & & & & & & & & & & \\
\hline J9 & & & & & & -1 & -1 & -1 & 1 & 1 & & & & & & \\
\hline J11 & & & & & & & & & & & 1 & & & & & \\
\hline $\mathrm{J} 14$ & & & & & & & & & & & & -1 & -1 & 1 & & \\
\hline J17 & & & & & & & & & & & & & & & -1 & -1 \\
\hline
\end{tabular}

\subsubsection{Calculation of Drainage Time by Combining a Major Washout Valve and Control Valves}

In Table $2 b$, it is found that the P5, P10, and P11 pipes are attributed to more than two washout valves. In practice, more than two washout valves can be utilized to efficiently drain excess water. However, only one washout valve is needed to simplify the implementation of the numerical algorithm. Two cases can be addressed in the drain direction matrix for one pipe having multiple washout valves: the horizontally sloped pipe, and the sloped pipe. In the case of the horizontally sloped pipe, the washout valve located at a lower elevation can be chosen as a major washout valve for calculating drain time. Therefore J3 and J11 can be chosen as a major washout valve for P5 and P10, respectively. This is practically persuasive because the draining flowrate highly depends on the magnitude of the water level from the drain node to the pipe. In the sloped pipe, assuming two sets of J9 and J11 composed of pipe elements, set J11 is a subset of set J9. In other word, set J9 contains P11 that is also the element of set J11. In this case, J11 can be chosen as a major washout valve for calculating drainage time because J11 can divide the draining role of the J9 valve. The results of major washout valve assignments are shown in Table 2c. By assigning a major washout valve to pipes, a function from a set of pipes to a set of washout valves can be defined. In other words, one pipe has only one washout valve to be drained. Following the numerical procedure of time integration, as shown in Figure 2, the drainage time of each pipe can be calculated as shown in Table 3. 
Table 3. Drainage time of pipes through an assigned major washout valve.

\begin{tabular}{cccccccccccccccccc}
\hline & P1 & P2 & P3 & P4 & P5 & P6 & P7 & P8 & P9 & P10 & P11 & P12 & P13 & P14 & P15 & P16 & Total \\
\hline J3 & -11 & -31 & 14 & 11 & 1 & & & & & & & & & & & & 68 \\
J9 & & & & & & -11 & -15 & -27 & 32 & 35 & & & & & & & 120 \\
J11 & & & & & & & & & & & 46 & & & & & & 46 \\
J14 & & & & & & & & & & & & -12 & -71 & 24 & & & 107 \\
J17 & & & & & & & & & & & & & & & -16 & -44 & 60 \\
\hline
\end{tabular}

From Table 3, the drainage time of each washout valve can be calculated by summing up the absolute value of drainage time of pipes; for example, the drainage time of J3 becomes 68 min by adding the drainage times of P1, P2, P3, P4, and P5. A control valve installed in the middle of the drainage zone can play an important role in reducing drainage time by splitting one drainage zone into two different sub-zones. By closing a control valve, a pipe segment can be divided into two smaller sub-segments, and the upstream and downstream of a drain zone can be isolated. For example, a control valve assigned to node J4 divides a set of pipes $\{$ P1, P2, P3, P4, P5 $\}$ into two sets of pipes (P1, P2 and P3) and (P4 and P5), which means that the washout valve of $\mathrm{J} 3$ can take one of the drainage times depending on the location of pipe breakage. Therefore, the drainage time $\left(T_{j}\right)$ of the washout valve $\mathrm{J} 3$ reduces $56 \mathrm{~min}$, which is a larger value of drainage time out of two different pipe subsets. If the maximum allowable drainage time is set to $100 \mathrm{~min}$, the sample transmission needs to reduce drainage time by adding a control valve in drainage zones J9 and J14. For example, after adding a control valve at junction $\mathrm{J} 8$, the updated drainage time of $\mathrm{J} 9$ becomes $94 \mathrm{~min}$, which is below the maximum drainage time, and the drainage time index $\left(\mathrm{I}_{T}\right)$ becomes 1 . This means that the sample water transmission line can satisfy all the drainage conditions and is ready to efficiently respond to pipe breakage.

\section{Results and Discussion}

First, in this section, the time integration method for calculating the drainage time is numerically validated with sample examples, focusing on the incorporation of friction effects. Then, the valve location method is applied to the CY transmission line, which is one of the BR water supply systems in South Korea that is currently being operated.

\subsection{Validation of the Time Integration Method for Calculating Drainage Time}

\subsubsection{Effect of Friction Loss on a Single Pipe}

A simulation was conducted on a single sloped pipe with a length of $5000 \mathrm{~m}$, a diameter of $1000 \mathrm{~mm}$, and an initial water level of $10.0 \mathrm{~m}$. The orifice diameter and flow coefficient are assumed to be $200 \mathrm{~mm}$ and 0.9 , respectively. The numerical analysis results, found by changing the Hazen-Williams roughness $\left(C_{H W}\right)$ to 150,100 , and 70 , were compared with the analytical solution integrated over time without the friction effect, as shown in Figure 5a. The analytical solution can be obtained by equating Equations (1) and (2), and summating the difference of water level over discrete time interval of $1 \mathrm{~min}$, as indicated by solid line (frictionless) in the figure. According to Figure 5a, the analytical solution without the friction effect took $330 \mathrm{~min}$ to fully drain. In contrast, the numerical results showed $333 \mathrm{~min}$ for $C_{H W}=150,338 \mathrm{~min}$ for $C_{H W}=100$, and $348 \mathrm{~min}$ for $C_{H W}=70$. The results can be interpreted that larger friction losses result in more drainage time. In addition, the smaller the loss due to friction, the closer the numerical analysis results to the analytical solution, which allowed the developed model to be validated. 


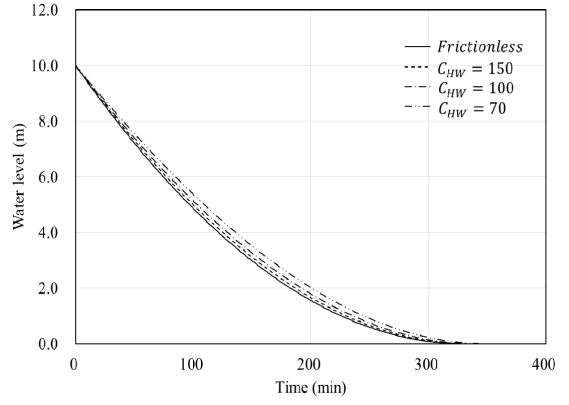

(a)

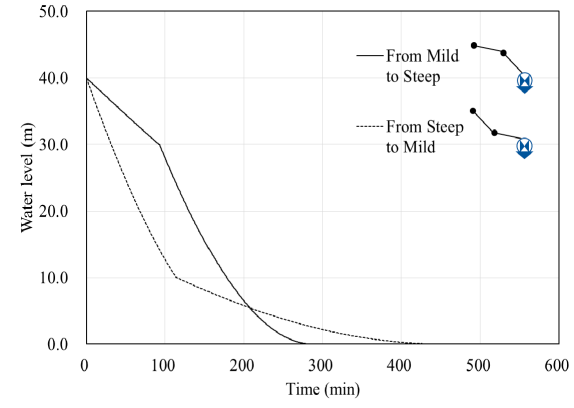

(b)

Figure 5. Drainage time: (a) friction effect on a single pipe; (b) serially connected pipes with the same properties.

\subsubsection{Numerical Analysis of Serially Connected Pipes}

Numerical analysis was performed for two pipes connected in series with a pipe length of $5000 \mathrm{~m}$, a pipe diameter of $1000 \mathrm{~mm}$, a pipe roughness coefficient of $C_{H W}=100$, and an initial water level of $40 \mathrm{~m}$. The simulation was performed for two drainage condition cases: the first case was connected from the mild slope (10 $\mathrm{m}$ water level) to the steep slope ( $30 \mathrm{~m}$ water level), the other was connected from the steep slope to the mild slope. The orifice diameter and flow coefficient are assumed to be $200 \mathrm{~mm}$ and 0.9, respectively. From the numerical results in Figure 5b, it can be seen that a large difference occurs in the drainage time, even though they have the same pipe length, pipe diameter, and friction conditions. In the case of a pipe system changing from a mild slope to a steep slope, it takes $287 \mathrm{~min}$ to drain, but for a pipe system changing from a steep slope to a mild slope, it takes $453 \mathrm{~min}$. The difference in drainage time of the two pipe systems can be explained by the fact that the drainage time was extremely long when a pipe had a mild slope close to the washout valve with little water level (or head difference). In more detailed explanation, considering two mildly sloped pipes, one of which is directly connected to the washout valve and the other is indirectly connected through a steeply sloped pipe, they have the same volume to be drained. In the orifice equation, the water level of $h$ for directly connected pipe is low, resulting in low flowrate in every time step compared to the indirectly connected one. The serially connected pipe example showed that different slope combinations could make considerable difference in drainage time.

\subsection{Practical Application of the Valve Location Method}

The developed valve location method, including drainage time integration, is applied to the $\mathrm{CY}$ transmission line of the BR multi-regional water supply system as shown in Figure 6. Through this practical application, the developed model shows its capability for improving the drain efficiency in real water transmission systems.

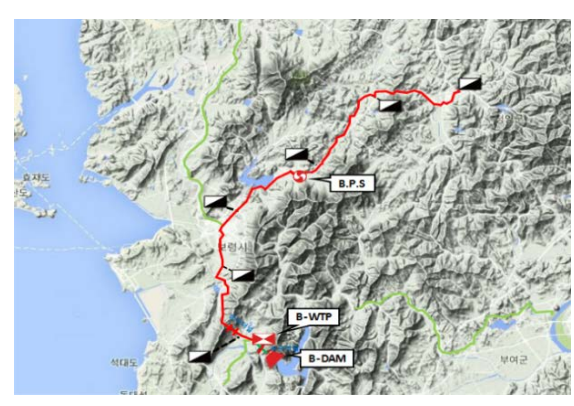

(a)

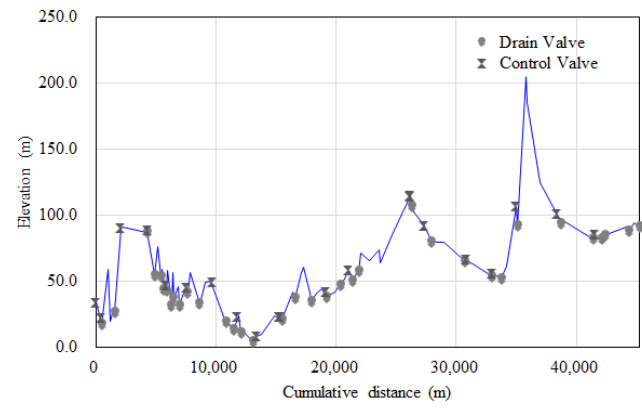

(b)

Figure 6. Schematic description of the CY transmission line in the BR water supply system: (a) plane view of the CY transmission line; (b) longitudinal profile of the CY transmission line. 
Description of the Study Area

Due to the lack of a drinking water source, the multi-regional water supply system has been built in Korea, which usually intakes water from one source of multi-purpose dams or rivers, purifies raw water to drinking water in water treatment plants, and conveys the treated water to the storage reservoirs of local cities. During the conveyance, large and long transmission lines are usually employed. The BR multi-regional water supply system, which is located on the west coast of South Korea, was chosen for the investigation of the applicability of the developed drainage algorithm. For simplicity of analysis, a CY water transmission line located in a hilly area was chosen, which is one of the BR transmission lines. The line is composed of a system of pipes totaling 45,261 $\mathrm{m}$ in length that are currently in operation and supplying water to the local cities. Input data for the analysis are composed of 89 pipes and 90 nodes. Other pipe properties are as follows: the length of pipes ranges from 9.3-2381.4 m, the diameters range from 300-2500 mm, and the roughness in terms of the Hazen-Williams coefficient ranges from 100 to 120 . Along the route of the transmission line, 31 washout valves with diameters of $200-400 \mathrm{~mm}$ and 22 control valves are installed.

\subsection{Modeling Results and Discussion}

Using the developed algorithm, the drain direction matrix is first derived for an existing network condition of $\mathrm{CY}$ transmission. From the results of the analysis, it is found that 31 existing washout valves do not fully cover the entire length of the transmission pipeline, although the number of washout valves is large enough compared with other transmission lines. More specifically, seven pipes, namely, P103, P104, P158, P159, P160, P161, and P162, do not have washout valves for excess water to be drained, and their length is $4625 \mathrm{~m}$ out of the total 45,261 $\mathrm{m}$. Moreover, three washout valves installed in J153, J164, and J167 are proven to be useless because the node sets are located on the convex longitudinal profile. Therefore, the CY transmission line can improve its efficiency for drainage and repair work after installing additional washout valves into J104 to drain P103 and P104, J159 to drain P158-P160, and J160 to drain P160-162. After creating 31 drainage zones with existing and additional washout valves as shown in Table 4, it is found that the drainage time is uneven, ranging from $2 \mathrm{~min}$ in drainage zone D20(J157) to $43 \mathrm{~min}$ in drain zone D11(J127), as shown in Figure 7a; this drainage time depends on the length of the pipe segment, the diameter of the transmission pipe, the diameter of the washout valve, and the topographical slope.

To improve the drainage time that exceeds the critical limits, water utilities can set the time depending on their circumstances, which is $30 \mathrm{~min}$ in the CY transmission line, and a control valve can be installed, as shown in Table 5. In this study, six drainage zones, namely, D11(J127), D12(J131), D13(J133), D24(J172), D28(J182), and D29(J186), exceed $30 \mathrm{~min}$. By adding control valves into six drainage zones, as shown in Table 5, it is found that drainage time is reduced to below $30 \mathrm{~min}$, as shown in Figure $7 \mathrm{~b}$. The reason why the installation of control valves reduces drainage time is that it can hold water in the pipe by dividing the drainage zone into two different segments.

Table 4. Drain direction matrix for the CY water transmission lines.

\begin{tabular}{|c|c|c|c|c|c|c|c|c|c|c|c|c|c|c|c|}
\hline & P101 & P102 & P103 & P104 & P105 & P106 & P107 & $\bullet \bullet \bullet$ & P183 & P184 & P185 & P 186 & P187 & P 188 & P189 \\
\hline \multicolumn{16}{|l|}{ J101 } \\
\hline J102 & -1 & 1 & & & & & & & & & & & & & \\
\hline \multicolumn{16}{|l|}{$\mathrm{J} 103$} \\
\hline J104 & & & -1 & 1 & & & & & & & & & & & \\
\hline \multicolumn{16}{|l|}{ J105 } \\
\hline \multicolumn{16}{|l|}{$\bullet \bullet \bullet$} \\
\hline J186 & & & & & & & & & & -1 & 1 & 1 & & & \\
\hline J187 & & & & & & & & & & & & & & & \\
\hline J188 & & & & & & & & & & & & & -1 & 1 & \\
\hline J189 & & & & & & & & & & & & & & & \\
\hline J190 & & & & & & & & & & & & & & & -1 \\
\hline No. of nodes & 1 & 1 & 1 & 1 & 1 & 1 & 2 & $\bullet \bullet \bullet$ & 0 & 0 & 1 & 1 & 1 & 1 & 1 \\
\hline
\end{tabular}




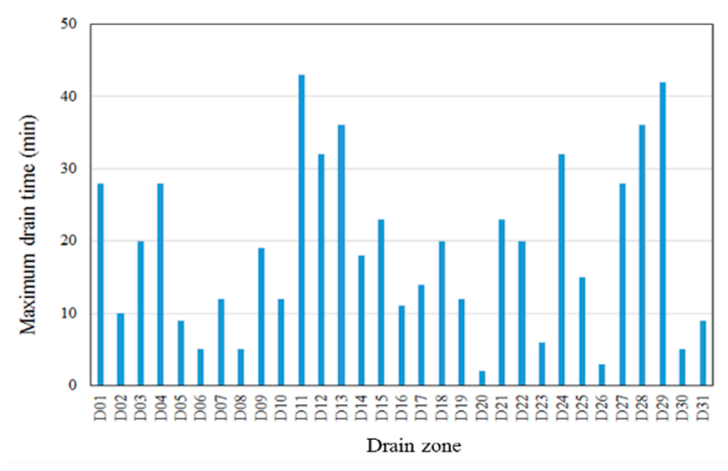

(a)

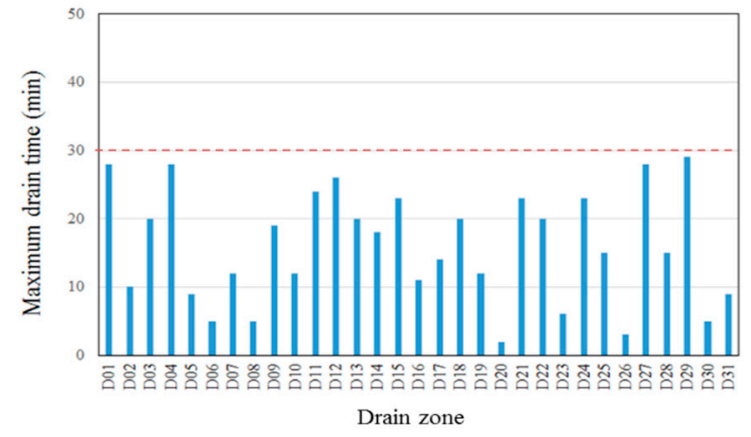

(b)

Figure 7. Drainage time: (a) before installing additional control valves; (b) after installing additional control valves.

Table 5. Drainage zone for the control valves to be installed.

\begin{tabular}{ccc}
\hline Drainage Zone & Connected Pipes & Additional Control Valves \\
\hline D11(J127) & P126-P128 & $\mathrm{J} 128$ \\
D12(J131) & P129-P131 & $\mathrm{J} 130$ \\
D13(J133) & $\mathrm{P} 132-\mathrm{P} 134$ & $\mathrm{~J} 134$ \\
D24(J172) & $\mathrm{P} 170-\mathrm{P} 172$ & $\mathrm{~J} 171$ \\
D28(J182) & $\mathrm{P} 181-\mathrm{P} 183$ & $\mathrm{~J} 183$ \\
D29(J185) & $\mathrm{P} 184-\mathrm{P} 186$ & $\mathrm{~J} 186$ \\
\hline
\end{tabular}

\section{Conclusions}

In this study, a valve location method was presented to effectively evaluate drainage coverage and drainage time when a water transmission pipe breaks. In order to accurately calculate the drainage time, the governing equations were formulated to incorporate friction head loss. The numerical method of time integration was suggested to reflect on the reduction in the water level over time, and the Newton-Raphson method was implemented to resolve nonlinear governing equations. In terms of drainage coverage over the entire transmission pipe line, the drainage coverage index and drainage time index were suggested to evaluate the spatial efficiency and temporal efficiency of pipe drainage, respectively. Moreover, a drain direction matrix was derived using a network searching algorithm, and feasible practical approaches, including critical horizontal slope, major washout valve, and control valve embedment, were presented.

The time integration method for drainage time was first validated with a single pipe example by comparing the drainage time of pipes with different roughness with that of a frictionless pipe. Then, a numerical application was performed to show the effect of water level for different combinations of slopes, from mild to steep, and steep to mild, in two serially connected pipes. The practical application of the valve location method to the $\mathrm{CY}$ water transmission line, which is a BR multi-regional water supply system, showed promising results for selecting washout and control valve locations. The results successfully identified the length of drainage zones that were not covered by existing washout valves to be $4625 \mathrm{~m}$ out of the total transmission length of $45,261 \mathrm{~m}$. In addition, with the help of a computerized program embedded in the developed method, it was found that three washout valves should be added to fully cover the entire transmission line, and six control valves should be added to ensure drainage time is below $30 \mathrm{~min}$. This study is only the first step to evaluate the reliability of the water transmission line in terms of drain efficiency by incorporating a washout valve as well as a control valve. The authors expect that further research will expand the developed method into a water distribution network with a more complex loop or network configuration. 
Author Contributions: Conceptualization, B.-H.S. and D.Y.C.; methodology, B.-H.S. and D.Y.C.; computerized program, D.Y.C.; supervision, K.J. and Z.W.G.; funding, Z.W.G. All authors have read and agreed to the published version of the manuscript.

Funding: This research was supported by the Energy Cloud R\&D Program through the National Research Foundation of Korea (NRF) funded by the Ministry of Science, ICT (2019M3F2A1073164).

Conflicts of Interest: The authors declare no conflict of interest.

\section{References}

1. Deb, A.K.; Hasit, Y.J.; Grablutz, F.M. Distribution System Performance Evaluation; AWWARF and AWWA: Denver, CO, USA, 1995.

2. Meniconi, S.; Brunone, B.; Ferrante, M.; Massari, C. Small amplitude sharp pressure waves to diagnose pipe systems. Water Resour. Manag. 2011, 25, 79-96. [CrossRef]

3. Meniconi, S.; Brunone, B.; Ferrante, M.; Capponi, C.; Carrettini, C.A.; Chiesa, C.; Segalini, D.; Lanfranchi, E.A. Anomaly pre- localization in distribution-transmission mains by pump trip: Preliminary field tests in the Milan pipe system. J. Hydroinform. 2015, 17, 377-389. [CrossRef]

4. Mounce, S.R.; Machell, J. Burst detection using hydraulic data from water distribution systems with artificial neural networks. Urban Water J. 2006, 3, 21-31. [CrossRef]

5. Geem, Z.W.; Tseng, C.-L.; Kim, J.; Bae, C.; ASCE. Trenchless water pipe condition assessment using artificial neural network. In Proceedings of the International Conference on Pipeline Engineering and Construction (Pipelines 2007), Boston, MA, USA, 8-11 July 2007.

6. Mounce, S.R.; Boxall, J.B.; Machell, J. Development and verification of an online artificial intelligence system for detection of bursts and other abnormal flows. J. Water Resour. Plan. Manag. 2012, 136, 309-318. [CrossRef]

7. Ye, G.; Fenner, R.A. Kalman filtering of hydraulic measurements for burst detection in water distribution systems. J. Pipeline Syst. Eng. Pract. 2011, 2, 14-22. [CrossRef]

8. Geem, Z.W. Multiobjective optimization of water distribution networks using fuzzy theory and harmony search. Water 2015, 7, 3613-3625. [CrossRef]

9. Choi, D.Y.; Kim, S.-W.; Choi, M.-A.; Geem, Z.W. Adaptive Kalman filter based on adjustable sampling interval in burst detection for water distribution system. Water 2016, 8, 142. [CrossRef]

10. Bouchart, F.; Goulter, I. Reliability improvements in design of water distribution networks recognizing valve location. Water Resour. Res. 1991, 27, 3029-3040. [CrossRef]

11. Walski, T.M. Water distribution valve topology for reliability analysis. Reliab. Eng. Syst. Saf. 1993, 42, 21-27. [CrossRef]

12. Hoff, J.W. Maintenance requirements of valves in distribution systems. In Proceedings of the Annual Conference AWWA, Toronto, ON, Canada, 23-27 June 1996.

13. Ysusi, M. System design: An overview. In Water Distribution Systems Handbook; Mays, L.W., Ed.; McGraw-Hill: New York, NY, USA, 2000.

14. Deb, A.K.; Snyder, J.K.; Hammell, J.O., Jr.; McCammon, S.B.; Jun, H.; Loganathan, G.V.; Grayman, W.M. Criteria for Valve Location and System Reliability; AWWARF and AWWA: Denver, CO, USA, 2006.

15. Jun, H.; Loganathan, G.V. Valve-controlled segments in water distribution systems. J. Water Resour. Plan. Manag. 2007, 133, 145-155. [CrossRef]

16. Jun, H.; Loganathan, G.V.; Kim, J.H.; Park, S. Identifying pipes and valves of high importance for efficient operation and maintenance of water distribution systems. Water Resour. Manag. 2008, 22, 719-736. [CrossRef]

17. Liu, H.; Walski, T.; Fu, G.; Zhang, C. Failure impact analysis of isolation valves in a water distribution network. J. Water Resour. Plan. Manag. 2017, 143, 04017019. [CrossRef]

18. Shuang, Q.; Liu, Y.; Tang, Y.; Liu, J.; Shuang, K. System reliability evaluation in water distribution networks with the impact of valves experiencing cascading failures. Water 2017, 9, 413. [CrossRef]

19. Liberatore, S.; Sechi, G.M. Location and calibration of valves in water distribution networks using a scatter-search meta-heuristic approach. Water Resour. Manag. 2009, 23, 1479-1495. [CrossRef]

20. Ali, M.E. Knowledge-based optimization model for control valve locations in water distribution networks. J. Water Resour. Plan. Manag. 2015, 141, 04014048. [CrossRef] 
21. De Paola, F.; Galdiero, E.; Giugni, M. Location and setting of valves in water distribution networks using a harmony search approach. J. Water Resour. Plan. Manag. 2017, 143, 04017015. [CrossRef]

22. Shin, B.-H. Drain Coverage Model for Efficiently Discharging Water from the Transmission Line in Case of Pipeline Breakage. Ph.D. Thesis, Chungnam National University, Daejeon, Korea, 2018.

(C) 2020 by the authors. Licensee MDPI, Basel, Switzerland. This article is an open access article distributed under the terms and conditions of the Creative Commons Attribution (CC BY) license (http://creativecommons.org/licenses/by/4.0/). 